\title{
The Causal Influence of Anxiety on Academic Achievement for Students of Differing Intellectural Ability
}

\author{
Darlene L. Heinrich \\ Florida State University
}

The present study examined the relationship between anxiety and learning within the context of drive theory and trait-state anxiety theory. It was hypothesized that trait anxiety (A-trait) would influence state anxiety (A-state), which in turn would influence academic achievement. The subjects were 86 students enrolled in a graduate education course for whom measures of A-state, A-trait, and achievement were obtained concurrently at three times during the course. GRE scores were used as measures of intellectual ability. Data were analyzed using the frequency-of-change-in-product-moment technique (Yee \& Gage, 1968), a causal analysis statistic which permits the determination of source and direction of causal influence in lagged correlational data. Results showed that A-trait influenced A-state and achievement, but the relationship between A-state and achievement was ambiguous. When intellectual ability was considered, A-trait was found to influence A-state and achievement, but only for high-ability students.

The relationship between anxiety and learning has been a topic of intense interest for psychologists and educators over the past quarter century. Much of the early research in this field tested hypotheses derived from drive theory (Taylor, 1956; Spence, 1958), which specifies that anxiety has a causal influence on performance:

APPLIED PSYCHOLOGICAL MEASUREMENT

Vol. 3, No. 3 Summer 1979 pp. 351-359

(c) Copyright 1979 West Publishing Co.
Anxiety $\rightarrow$ Performance.

In general, high anxiety has been found to facilitate performance on easy learning tasks and to contribute to performance decrements on difficult tasks (Spence \& Spence, 1966).

Recent research on anxiety and learning has been greatly influenced by Cattell and Scheier's (1958) distinction between state and trait anxiety. In formulating a trait-state theory of an xiety and behavior, Spielberger (1966a) defines state anxiety (A-state) as a transitory emotional reaction that consists of feelings of tension and apprehension, and arousal of the autonomic nervous system. Trait anxiety (A-trait) refers to relatively stable individual differences in anxiety proneness, i.e., to differences in the disposition to perceive the world as dangerous or threatening and to experience elevations in A-state.

Anxiety states vary in intensity and fluctuate over time as a function of the stresses that impinge upon an individual. In situations that pose direct or implied threats to self-esteem, traitstate anxiety theory holds that high A-trait persons experience higher levels of state anxiety than persons who are low in A-trait (Spielberger, 1972). Although trait anxiety does not directly influence performance, A-trait influences level of A-state, and A-states have motivational or drive properties that influence performance. 
The causal relationships posited by trait-state anxiety theory may be expressed as follows:

$$
\mathrm{T} \rightarrow \mathrm{S} \rightarrow \mathrm{P} \text {. }
$$

In investigations of anxiety and learning, an analysis of variance (Anova) research paradigm is typically used to evaluate anxiety-performance relationships. Trait anxiety is generally conceptualized as the independent variable, and subjects are classified as high or low anxious on the basis of their scores on measures such as the Taylor (1953) Manifest Anxiety Scale or the State-Trait Anxiety Inventory (STAI; Spielberger, Gorsuch, \& Lushene, 1970). The performance of high- and low-anxiety groups is then compared using Anova statistical techniques.

A major weakness with Anova research designs in studies of anxiety and learning is that the investigator cannot randomly assign subjects to high- and low-anxiety groups. Even though many investigators conceptualize trait anxiety as an experimental (manipulated) independent variable, the actual data generated by such designs are correlational in nature, and causality cannot readily be determined. However, recent advances in causal analysis techniques provide an empirical basis for inferring causal relations from correlational data.

A variety of causal analysis procedures have been developed (Heise, 1975), the most prominent of which are path analysis and the crosslagged-panel-correlation technique. Both causal analysis procedures begin with an explicit theoretical statement of the causal relationships that are hypothesized among a set of variables. Path analysis assumes causality, then estimates the magnitude of the direct and indirect effects of certain variables on certain others. In contrast, the cross-lagged-panel-correlation technique tests the relationship between variables to determine which, if either, is a causal agent. The cross-lagged-panel-correlation technique operationalizes the rule of time precedence as a fundamental premise for inferring causality by using panel data, i.e., data collected on the same two or more variables on the same individuals at two or more points in time.

While the cross-lagged-panel-correlation technique is useful for identifying a causal variable (the source of influence), it does not permit the determination of direction of influence, i.e., whether the causal variable results in increases or decreases in the dependent variable. Yee and Gage (1968) have developed a causal analysis procedure, the frequency-of-change-in-productmoment (FCP) technique for use with panel data, which permits identification of both source and direction of causal influence.

The FCP technique was used in a recent study by King, Heinrich, Stephenson, and Spielberger (1976) that investigated causal relationships between trait anxiety, state anxiety, and academic achievement in two college courses. King et al. (1976) reported evidence that trait anxiety influenced state anxiety and that both trait and state anxiety influenced achievement; however, they were unable to determine the direction of causal influence.

Some research has suggested that the influence of anxiety on performance may depend upon the intellectual ability of the student. In particular, Denny (1966) and Spielberger (1966b) have observed that high anxiety is associated with superior performance for high ability college students and with performance decrements for students of low ability. In the present study, the Yee-Gage FCP technique was used to evaluate the source and direction of causal influence between anxiety and performance in a university course for graduate students with high and low intellectual ability. On the basis of previous research, it was predicted that trait anxiety would influence state anxiety and that A-state would facilitate performance for high-ability students and would lead to performance decrements for students with low ability.

\section{Method}

\section{Subjects}

The subjects were 86 graduate students enrolled during one of four consecutive academic 
quarters in an "Introduction to Educational Research" course. This course was taught by the same instructor each quarter and was required for most doctoral students in the College of Education. In the analyses of casual relations, data were available for varying numbers of students because of absences from class on one or more of the three occasions on which the research instruments were administered. Complete data were available for 68 of the students for all three occasions of measurement, and Graduate Record Examination (GRE) scores were available for 59 of these students. GRE scores (verbal plus quantitative) ranged from 640 to 1470 , with a median score of 1060 (mean $=1065, S . D .=165$ ). Thus, a wide range of intellectual ability was represented in the sample.

\section{Procedure}

A diagnostic pretest was administered to each class at the beginning of the term, and the STAI (Spielberger et al., 1970) was given immediately following this pretest examination. The STAI Astate scale was first administered with modified instructions which asked students to report how they felt while taking the pretest. The STAI Atrait scale was then given with standard instructions ("Indicate how you generally feel"). The STAI A-state and A-trait scales were readministered with these same instructions immediately following the midterm examination and again at the end of the quarter, following the final exam.

\section{Analysis of Data}

The Yee-Gage (1968) FCP technique requires that all variables under consideration (i.e., Atrait, A-state, performance) be measured concurrently for each subject on two or more occasions. For each variable, the distribution of raw scores is converted to $z$ scores, and the crossproducts of specific combinations of $z$ scores for each subject are then classified according to one of four competing hypotheses. With respect to the direction of influence, cross-products that show an algebraic increase at the next measurement period are said to have changed congruently (i.e., one variable increases the other); those that show an algebraic decrease over time are said to have changed incongruently (i.e., one variable decreases the other). When the direction of change is congruent, the variable whose premeasure was part of the more positive product is considered to be the source of influence. When the direction of influence is incongruent, the variable whose premeasure was part of the more negative product is considered to be the source of influence.

In the hypotheses listed below, $z$ refers to a subject's $z$ scores for state anxiety (S) or for performance $(\mathrm{P})$, and the subscripts 1 and 2 refer to the pretest and midterm, respectively.

$$
\text { If } z_{S 1} z_{P 1}<z_{S 2} z_{P 2} \text {, then change is congruent (C), }
$$
and

1. if $z_{S 1} z_{P 2}>z_{S 2} z_{P 1}$, then A-state is the source of influence (SC),

2. if $z_{S 1} z_{P 2}<z_{s 2} z_{P_{1}}$, then performance is the source of influence (PC).

If $z_{S 1} z_{P 1}>z_{s 2} z_{P 2}$, then change is incongruent (I), and

3. if $z_{s 1} z_{P 2}>z_{s 2} z_{P 1}$, then performance is the source of influence (PI),

4. if $z_{s 1} z_{P 2}<z_{s 2} z_{P 1}$, then A-state is the source of influence (SI).

It should be noted that while the FCP technique is appropriate for lagged correlational data, it does not rule out the possibility that a third variable may be responsible for the relationship between the other two variables.

It has been noted that the FCP technique occasionally misclassifies subjects because decisions for source and direction are made on the basis of products of $z$ scores. Errors occur when two variables both increase over time, but the product of signed $z$ scores becomes more negative because one variable is positive and the other is negative. This potential difficulty was eliminated in the present study by transforming raw scores to $T$-scores with a mean of 50 (S.D. $=$ 10) so that all scores would be positive. 
In this study, source and direction of causal influence were evaluated for each of the three pairs of variables (trait and state anxiety; trait anxiety and performance; state an xiety and performance). Thus, for each pair of variables, three FCP analyses were performed: (1) pretest vs. midterm test scores $\left(t_{1} t_{2}\right) ;(2)$ pretest vs. final test scores $\left(t_{1} t_{3}\right)$; and (3) midterm vs. final test scores $\left(t_{2} t_{3}\right)$. In each of these analyses, the data for individual subjects were classified according to the source and direction of influence. For example, in evaluating the relationship between state anxiety and performance, the source and direction categories were state-anxiety-congruent (SC) or incongruent (SI) change; or performance-congruent (PC) or incongruent (PI) change.

To determine source of influence independent of direction, the data for the source categories were combined (e.g., for A-state and performance: SC + SI vs. PC + PI), and chi-squares were computed. When the chi-square for a particular source of influence was significant, the direction of influence was subsequently evaluated by a chi-square analysis of congruent vs. incongruent frequencies for that source variable. Thus, if state anxiety were determined to be the causal variable, the frequencies of SC vs. SI were evaluated to determine whether the direction of change could be identified as congruent or incongruent.
Four competing hypotheses were tested for each pair of variables, e.g., for state an xiety and performance, the following hypotheses were tested: (1) increases in A-state cause increases in performance (SC); (2) increases in A-state cause decrements in performance (SI); (3) increases in performance cause increases in A-state (PC); and (4) increases in performance cause decrements in A-state (PI).

\section{Results}

Table 1 presents the means and standard deviations for the STAI A-state and A-trait scales and the performance scores of the 68 students for whom complete data were available for these three variables on all three occasions of measurement. The A-trait means for the pretest, the midterm, and the final examination sessions were relatively stable across the three measurement periods; an Anova for these data indicated that the differences in the means could be attributed to chance, $F(2,134)=.51, p>.05$. In contrast, state anxiety fluctuated as a function of examination stress, increasing from the pretest period to the midterm examination and remaining high during the final examination, $F(2$, $134)=11.23, p<.01$. Since the pretest, midterm, and final examinations consisted of differing numbers of items, no meaningful com-

\section{Table 1}

Means and Standard Deviations of Anxiety and Performance Measures for 68 Subjects with Complete Data for Three Measurement Periods.

\begin{tabular}{lccc}
\hline Measure & Pretest $\left(t_{1}\right)$ & Midterm $\left(t_{2}\right)$ & Final $\left(t_{3}\right)$ \\
\hline Trait Anxiety & 33.43 & 32.97 & 33.21 \\
M & 6.86 & 7.40 & 8.88 \\
SD & & & \\
State Anxiety & 37.50 & 43.82 & 41.74 \\
M & 9.07 & 11.09 & 11.92 \\
SD & & & \\
Performance & 31.31 & 27.03 & 30.04 \\
M & 6.75 & 2.91 & 6.49 \\
SD & 56 & 33 & 39 \\
Number of Items & & & \\
\hline
\end{tabular}


parisons could be made for the students' performance scores. However, as can be noted in Table 1, there was considerably less variability in midterm performance scores than for the pretest or the final examination.

In the FCP analyses of causal relationships for each pair of variables, complete data were available for 71 students in the $t_{1} t_{2}$ analysis and for 75 students in the $t_{1} t_{3}$ analysis and in the $t_{2} t_{3}$ analysis. The results of the FCP analyses for the source and direction of causal influence are presented in Table 2. For source of influence between A-trait and A-state, the chi-squares for all three comparisons were significant. In each of these analyses, the number of instances in which
T influenced $\mathrm{S}$ was greater than those in which $\mathrm{S}$ influenced $\mathrm{T}$, indicating that $\mathrm{A}$-trait was the causal variable.

Trait anxiety also emerged as the causal variable in all three analyses of the relationship between A-trait and performance. With respect to the direction of influence in these analyses, since the number of cases of congruent and incongruent change were approximately equal, it was not possible to specify the direction in which Atrait influenced either A-state or performance.

In the relationship between A-state and performance, no causal influence pattern could be identified. A-state influenced performance as often as performance influenced A-state, as can

Table 2

FCP Analyses of the Source and Direction of Causal Influence

\begin{tabular}{|c|c|c|c|c|c|c|c|}
\hline \multicolumn{8}{|c|}{ A-Trait and A-State } \\
\hline \multirow{2}{*}{$\begin{array}{c}\text { Test } \\
\text { Periods }\end{array}$} & \multirow[b]{2}{*}{$N$} & \multicolumn{2}{|c|}{ I Influences S } & \multicolumn{2}{|c|}{$\mathrm{S}$ Influences $\mathrm{T}$} & \multicolumn{2}{|c|}{ Chi-Square } \\
\hline & & $\begin{array}{c}\text { Con } \\
\text { gruent }\end{array}$ & $\begin{array}{l}\text { Incon } \\
\text { gruent }\end{array}$ & $\begin{array}{c}\text { Con } \\
\text { gruent }\end{array}$ & $\begin{array}{l}\text { Incon } \\
\text { gruent }\end{array}$ & $\frac{\text { Lini- }}{\text { Source }}$ & Direction \\
\hline$t_{1} t_{2}$ & 71 & 23 & 22 & 15 & 71 & $5.08^{\star}$ & .02 \\
\hline$t_{1} t_{3}$ & 75 & 26 & 29 & 10 & 10 & $16.33 * \star$ & .16 \\
\hline$t_{2} t_{3}$ & 75 & 26 & 22 & 11 & 13 & $5.88^{\star}$ & .33 \\
\hline
\end{tabular}

A-Trait and Performance

\begin{tabular}{|c|c|c|c|c|c|c|c|}
\hline \multirow{2}{*}{$\begin{array}{l}\text { Test } \\
\text { eriods }\end{array}$} & \multirow[b]{2}{*}{$\mathrm{N}$} & \multicolumn{2}{|c|}{ I Influences $P$} & \multicolumn{2}{|c|}{ P Influences T } & \multicolumn{2}{|c|}{ Chi-Square } \\
\hline & & $\begin{array}{c}\text { Con } \\
\text { gruent }\end{array}$ & $\begin{array}{l}\text { Incon } \\
\text { gruent }\end{array}$ & $\begin{array}{c}\text { Con } \\
\text { gruent }\end{array}$ & $\begin{array}{l}\text { Incon } \\
\text { gruent }\end{array}$ & Source & Direction \\
\hline$\overline{t_{1} t_{2}}$ & 71 & 27 & 24 & 14 & 12 & $5.08^{\star}$ & .20 \\
\hline$t_{7} t_{3}$ & 75 & 21 & 28 & 14 & 12 & $7.05 *$ & 1.00 \\
\hline$t_{2} t_{3}$ & 75 & 26 & 23 & 13 & 13 & $7.05 *$ & .18 \\
\hline
\end{tabular}

A-State and Performance

Test

Periods N

\begin{tabular}{cccc}
\hline$t_{1} t_{2}$ & 71 & 22 & 16 \\
$t_{1} t_{3}$ & 75 & 15 & 20 \\
$t_{2} t_{3}$ & 75 & 13 & 19 \\
$\star_{p}<.05 ;$ & $\star \star p$ & $<.01$ &
\end{tabular}

Chi-Square Source Direction 
be noted in Table 2. Since the source of causal relationship between A-state and performance could not be established, it was not meaningful to evaluate the direction of influence for these relationships.

In order to evaluate the effects of intellectual ability on the source and direction of causal influence, separate FCP analyses were conducted for those students for whom GRE scores were available. Students whose GRE scores were above the median GRE score of 1060 for the total sample were designated as the high-ability group; those with GRE scores below the median were designated as the low-ability group.

The FCP analyses for the 30 high- and 29 lowability students are reported in Table 3 . For the high-ability students, A-trait exerted a significant causal influence on A-state in all three comparisons. Trait anxiety also influenced performance in the $t_{1} t_{2}$ analysis for the high GRE students, but none of the chi-squares were significant in the corresponding analyses for direction of influence.

No causal relationships between A-trait and performance were identified in the $t_{1} t_{3}$ and $t_{2} t_{3}$ FCP analyses for high-ability students, nor between A-state and performance in any of the FCP analyses for these students. For the lowability students, no causal influence patterns emerged in any of the FCP analyses, as can be noted in Table 3. Since no source variables were identified in these analyses, calculations for direction of influence were not appropriate.

\section{Discussion}

The present study tested predictions from drive theory and trait-state anxiety theory with regard to causal relationships among anxiety and performance variables for graduate students enrolled in an educational research course. The predictions that were tested specified that trait anxiety influences state anxiety, which in turn influences academic performance:

$$
\mathrm{T} \rightarrow \mathrm{S} \rightarrow \mathrm{P} .
$$

A strong relationship was found between trait and state anxiety, with A-trait emerging as the causal variable. This finding was consistent with the prediction from trait-state anxiety theory (Spielberger, 1966; 1972) that $\mathrm{T} \rightarrow \mathrm{S}$. A causal relationship between trait anxiety and performance was also found, $T \rightarrow P$, providing support for the drive theory prediction that anxiety influences performance. These findings also replicate the results of King et al. (1976).

With respect to state anxiety and performance, no source of causal influence could be identified, i.e., state anxiety influenced performance in as many cases as performance influenced A-state. These findings suggest that performance tests not only measure achievement but may also serve as stressors. In the present study, the performance tests were apparently perceived as threatening by some students and thus influenced state anxiety: $\mathbf{P} \rightarrow \boldsymbol{S}$. But for some students, individual differences in state anxiety also seemed to influence performance: $S \rightarrow P$. Thus, the relationship between A-state and performance may be a reciprocal one, which may be depicted as $S \leftrightarrow P$.

The findings that trait anxiety influenced both state anxiety and performance, and that $\mathrm{A}$ state and performance seemed to have a reciprocal influence upon one another, suggest the need for a revised model. The following predictive model would seem to be most consistent with the results of this study:

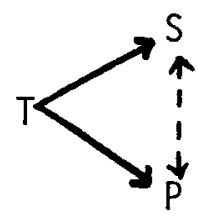

The students in the present study represented a wide range of intellectual ability, which permitted evaluation of hypotheses derived from Spielberger's (1966b) extension of drive theory to incorporate individual differences in intelligence. In the FCP analyses of the relationships among state anxiety, trait anxiety, and per- 
Table 3

FCP Analyses of the Effects of Ability on the Source and Direction of Causal Influence

\begin{tabular}{|c|c|c|c|c|c|c|}
\hline \multicolumn{7}{|c|}{ A-Trait and A-State } \\
\hline \multirow{2}{*}{$\begin{array}{l}\text { Test Periods } \\
\text { and } \\
\text { Ability Group }\end{array}$} & \multicolumn{2}{|c|}{ I Influences $S$} & \multicolumn{2}{|c|}{ S Influences T } & \multicolumn{2}{|c|}{ Chi-Square } \\
\hline & $\begin{array}{c}\text { Con } \\
\text { gruent }\end{array}$ & $\begin{array}{l}\text { Incon } \\
\text { gruent }\end{array}$ & $\begin{array}{c}\text { Con } \\
\text { gruent }\end{array}$ & $\begin{array}{l}\text { Incon } \\
\text { gruent }\end{array}$ & Source & Direction \\
\hline$t_{1} t_{2}$ & & & & & & \\
\hline High GRE & 11 & 10 & 4 & 5 & $4.80^{*}$ & .05 \\
\hline Low GRE & 8 & 7 & 8 & 6 & .03 & \\
\hline$t_{1} t_{3}$ & & & & & & \\
\hline High GRE & 12 & 11 & 5 & 2 & $8.53 *$ & .04 \\
\hline LOW GRE & 10 & 9 & 5 & 5 & 2.79 & \\
\hline t2t3 & & & & & & \\
\hline High GRE & 10 & 11 & 4 & 5 & $4.80 *$ & .05 \\
\hline Low GRE & 9 & 9 & 7 & 4 & 1.69 & \\
\hline
\end{tabular}

A-Trait and Performance

\begin{tabular}{|c|c|c|c|c|c|c|}
\hline \multirow{2}{*}{$\begin{array}{l}\text { Test Periods } \\
\text { and } \\
\text { Ability Group }\end{array}$} & \multicolumn{2}{|c|}{ T Influences $P$} & \multicolumn{2}{|c|}{ P Influences T } & \multicolumn{2}{|c|}{ Chi-Square } \\
\hline & $\begin{array}{c}\text { Con } \\
\text { gruent }\end{array}$ & $\begin{array}{l}\text { Incon } \\
\text { gruent }\end{array}$ & $\begin{array}{c}\text { Con } \\
\text { gruent }\end{array}$ & $\begin{array}{l}\text { Incon } \\
\text { gruent }\end{array}$ & Source & Direction \\
\hline$t_{17 t 2}$ & & & & & & \\
\hline $\begin{array}{l}\text { High GRE } \\
\text { Low GRE }\end{array}$ & $\begin{array}{r}10 \\
9\end{array}$ & $\begin{array}{r}12 \\
9\end{array}$ & $\begin{array}{l}5 \\
6\end{array}$ & $\begin{array}{l}3 \\
5\end{array}$ & $\begin{array}{l}6.53^{\star} \\
1.69\end{array}$ & .18 \\
\hline$t_{1} t_{3}$ & & & & & & \\
\hline High GRE & 7 & 12 & 7 & 4 & 2.73 & \\
\hline LOW GRE & 11 & 8 & 5 & 5 & 2.79 & \\
\hline$t_{2} t_{3}$ & & & & & & \\
\hline High GRE & 7 & 10 & 6 & 7 & .53 & \\
\hline Low GRE & 10 & 8 & 5 & 6 & 1.69 & \\
\hline
\end{tabular}

A-State and Performance

\begin{tabular}{|c|c|c|c|c|c|c|}
\hline \multirow{2}{*}{$\begin{array}{c}\text { Test Periods } \\
\text { and } \\
\text { Ability Group }\end{array}$} & \multicolumn{2}{|c|}{$\mathrm{S}$ Influences $\mathrm{P}$} & \multicolumn{2}{|c|}{ P Influences $\mathrm{S}$} & \multicolumn{2}{|c|}{ Chi-Square } \\
\hline & $\begin{array}{c}\text { Con } \\
\text { gruent }\end{array}$ & $\begin{array}{l}\text { Incon } \\
\text { gruent }\end{array}$ & $\begin{array}{c}\text { Con } \\
\text { gruent }\end{array}$ & $\begin{array}{l}\text { Incon } \\
\text { gruent }\end{array}$ & Source & Direction \\
\hline$t_{1} t_{2}$ & & & & & & \\
\hline High GRE & 10 & 7 & 6 & 7 & .53 & \\
\hline LOW GRE & 10 & 6 & 7 & 6 & .31 & \\
\hline$t_{1} t_{3}$ & & & & & & \\
\hline High GRE & 7 & 4 & 10 & 9 & 2.13 & \\
\hline Low GRE & 4 & 8 & 7 & 10 & .55 & \\
\hline$t_{2} t_{3}$ & & & & & & \\
\hline High GRE & 6 & 5 & 10 & 9 & 2.13 & \\
\hline LOW GRE & 5 & 9 & 5 & 10 & .03 & \\
\hline
\end{tabular}


formance for students with high and low ability, it was found that A-trait exerted a significant causal influence on A-state, but only for the high-ability students. For low-ability students, no causal influence patterns were identified.

In the FCP analyses for high- and low-ability students, it was necessary to eliminate 12 to 16 students because of missing data. Most of these students had never taken the GRE, but some were absent or postponed taking these exams. For almost all of these students, trait anxiety influenced performance. Thus, the loss of a disproportionate number of $T \rightarrow P$ students clearly biased the causal analyses for the high- and lowability students, suggesting that students whose anxiety influenced their performance were more likely to avoid taking the GRE and/or to absent themselves from class during course exams.

In this study, the inability to determine the direction of influence of A-trait and A-state on performance may have resulted from a limitation in the Yee-Gage model. According to Yap (1974), when time 1 (initial) measures are uncorrelated, the FCP model is effective; but when time 1 measures are correlated, only the source of influence is likely to be correctly identified, and estimates of the direction of influence tend to be ambiguous. In the present study, A-trait was correlated .58 with A-state and .24 with performance for the pretest (time 1) measures.

In summary, the results of the present study provide evidence that trait anxiety has a causal influence on state anxiety and on performance in course examinations. The results also suggested that there may be a reciprocal relationship between state anxiety and performance. While trait anxiety influenced performance for high-ability students, no causal relationships between anxiety and performance were found for students with low ability. There was no evidence with regard to the direction of causal influence in the present study, but the power of the YeeGage (1968) model appears to be limited in the evaluation of directionality for variables that are moderately correlated, as was the case for trait and state anxiety and performance in this study.

\section{References}

Cattell, R.B., \& Scheier, I.H. The nature of anxiety: A review of 13 multivariate analyses composing 814 variables. Psychological Reports Monographs Supplement, 1958, 5, 351-388.

Denny, J.P. Effects of anxiety and intelligence on concept formation. Journal of Experimental Psychology, 1966, 72, 596-602.

Heise, D.R. Causal analysis. New York: John Wiley \& Sons, 1975.

King, F.J., Heinrich, D.L., Stephenson, R.S., \& Spielberger, C.D. An investigation of the causal influence of state and trait anxiety on academic achievement. Journal of Educational Psychology. $1976,68,330-334$.

Spence, K.W. A theory of emotionally based drive (D) and its relation to performance in simple learning situations. American Psychologist, 1958, 13. 131-141.

Spence, J.T., \& Spence, K.W. The motivational components of manifest anxiety: Drive stimuli. In C.D. Spielberger (Ed.), Anxiety and behavior. New York: Academic Press, 1966.

Spielberger, C.D. The effects of anxiety on complex learning and academic achievement. In C.D. Spielberger (Ed.), Anxiety and behavior. New York: Academic Press, 1966. (a)

Spielberger, C.D. Theory and research on anxiety. In C.D. Spielberger (Ed.), Anxiety and behavior. New York: Academic Press, 1966. (b)

Spielberger, C.D. Anxiety as an emotional state. In C.D. Spielberger (Ed.), Anxiety: Current trends in theory and research (Vol. 1). New York: Academic Press, 1972.

Spielberger, C.D., Gorsuch, R.L., \& Lushene, R.E. Manual for the State-Trait Anxiety Inventory. Palo Alto, CA: Consulting Psychologists Press, 1970.

Taylor, J.A. A personality scale of manifest anxiety. Journal of Abnormal and Social Psychology, 1953, $48,285-290$.

Taylor, J.A. Drive theory and manifest anxiety. Psychological Bulletin. 1956, 53, 303-320.

Yap, K.O. A study of the efficiency of causal analysis conducted on panel data. (Doctoral dissertation, University of Hawaii, 1973.) Dissertation $A b$ stracts International, 1973, 35, 901 A. (University Microfilms No. 74-17, 395)

Yee, A.H., \& Gage, N.L. Techniques for estimating the source and direction of causal influence in panel data. Psychological Bulletin. 1968, 70 , $115-126$. 


\section{Acknowledgment}

This article is based on the author's doctoral dissertation. submitted to the Educational Psychology program of the Florida State University. The assistance of $F$. J. King and Charles D. Spielberger is gratefully acknowledged.

\section{Author's Address}

Send requests for reprints or further information to Darlene L. Heinrich, Learning Systems Institute, Florida State University, Tallahassee, FL 32306. 